Bentham open

RESEARCH ARTICLE

\title{
The Role of Art in Society with Particular Reference to the Problem of Violence $^{\text {s }}$
}

\author{
Camilla Pagani ${ }^{*}$
}

Institute of Cognitive Sciences and Technologies, National Research Council, Via San Martino della Battaglia 44, 00185 Roma, Italy

\section{Abstract:}

\section{Background:}

According to the Latin poet Virgil, art is capable of revealing to us what no science can ever reveal to a human mind. The main thesis of this paper is that art can play an extremely beneficial role in society as it can strongly foster humans' efforts to attain a deeper and broader comprehension of reality.

\section{Objective:}

The experience of art can provide a powerful contribution to the efforts to avoid resorting to violence and to address conflicts constructively. Violence or, more exactly, unjustified violence, basically rests on an irrational and short-sighted analysis and interpretation of reality.

\section{Results:}

The psychological processes relating to the aesthetic experience and to its connections with violence are described. It is also pointed out that this theoretical perspective does not fully coincide with the theoretical theses underpinning art therapy. In fact, in this paper art is not considered as a mere therapeutic instrument. Instead, an attempt has been made to consider art and our relationship with art in their more complex and partly still unexplored aspects, where neither art or the individual is "at the service" of the other.

\section{Conclusion:}

Art can provide the possibility to experience a new dimension, where no power relations exist and where new ways of seeing and feeling are made possible. It can hence foster the development of less primitive and richer personalities. In this way violence should lose its raison d'être. So it appears that this theoretical approach might be particularly helpful in order to better understand and countervail violence.

Keywords: Aesthetic experience, Art therapy, Artistic form, Freedom, Knowledge, Power relations, Society, Violence.

\section{INTRODUCTION}

The considerations I will present in this paper constitute the first stage of an exploratory study conducted on the nature of the aesthetic experience and its connections with human attitudes and behavior. I will try to focus on the role of art in society as a whole. This means I will not deal, for example, on its role and function in the context of special

\footnotetext{
* Address correspondence to this author at the Institute of Cognitive Sciences and Technologies, National Research Council, Via San Martino della Battaglia 44, 00185 Roma, Italy; Tel: 003906 44595311; Fax: 003906 44595243; E-mails: camilla.pagani@istc.cnr.it, camilla_pagani@yahoo.it

${ }^{\$}$ This article is partly based on a paper presented at the International Conference "Violencia, Guerra y Postconflicto, XL Coloquios Internacionales Sobre Cerebro y Agresión - CICA", Bogotà (Colombia), 12-14 November 2015. Many thanks to the anonymous reviewer for particularly significant comments and suggestions.
} 
groups - for example therapeutic groups, as is the case with art therapy. In a way, my scope is broader.

I will analyze the role of art in society with particular reference to the problem of violence. In scientific literature, this issue has sometimes been addressed from a specific point of view, namely the possibility of a correlation between violent crimes and the experience of some particular kinds of art [1]. Here, my point of view is very different.

Elsewhere [2], I proposed a definition of violence which comprises both physical and psychological violence and includes behaviors, thoughts, and emotions. In the same context, I also underlined the complex nature of the phenomenon of violence and, similarly, the complex nature of "the various cognitive and emotional processes through which the human mind should examine and evaluate it" (p. 11), which means that the complexity of these processes "should be a requisite both of scientists and of lay people" (p. 11).

Robustelli [3] wrote that "in its deepest meaning violence is what limits freedom" (p. 96). This is a definition I strongly support, provided that we clarify what we mean by "freedom." In my view, as well as in Robustelli's view as far as we can infer from his writings, basically freedom represents humans' capacity to be fully aware of and express their cognitive and emotional potentialities. This is an important point, all the more that, later on, I will especially focus on freedom as an inherent component of the aesthetic experience.

I am here using the term "violence" in its traditionally negative meaning, namely as "unjustified violence." There may be some extreme cases (e.g., if an adult is killing a child) where violence, aiming to defend someone, is arguably justified.

Indeed, violence, or more exactly, unjustified violence, basically rests on an irrational and short-sighted analysis and interpretation of reality [3 - 5]. Elsewhere, I analyzed the delicate relationship between complex thinking and attitudes towards cultural diversity [6] just as the delicate relationship between complex thinking and empathy [7,8]. The data from our previous research indicate a positive connection between complex thinking and a deep interest in culturally diverse people [6 - 8]. Our data also indicate that the deep interest is often accompanied by an empathic attitude toward these people. Instead, a "mutilating" [9] (p. 57) and impoverished thought generally characterizes violent attitudes and behaviour [10]. Our research findings show that youths' racist attitudes are often characterized by "the poverty and limitedness of their cognitive and emotional processes" [6] (p. 27).

In some previous papers [7, 8, 11 - 13] I referred to the role of art, with special emphasis on literature and music, in fostering empathic attitudes towards individuals belonging to different cultures. Following are three quotes from three papers:

[...] the role of literature, as well as of other kinds of artistic expression, in developing empathy can be particularly notable [...]. Literature allows deep ideas and emotions to be expressed and, hence, makes it possible for the reader to participate in other human beings' experiences, even if these human beings are fictitious and belong to different cultures. As a result, these characters in the stories become specific individuals with their own stories and personalities, empathy is promoted and the tendency to homogeneity diminishes ${ }^{1}[13]$ (p. 257).

Through the experience of art people from all cultures can more easily and more deeply become aware of a superordinate identity they belong to, which is constituted by their common fate as human beings and by the common core of their psyche. This includes such universal feelings as hope, love, hate, suffering, fear, regret, and peacefulness, while at the same time preserving the awareness of the salience of their specific (e.g., cultural, psychological, etc.) subgroup identity. It is well known that during World War II, the famous German song "Lili Marleen" was sung by soldiers from the armies of both fronts, as Stanley Kramer showed in 1961 in his famous film "Judgment at Nuremberg” [12] (p. 308).

Although she belongs to a western cultural context, the South African writer Nadine Gordimer expressed her commitment in her works to an empathic understanding between White culture and the other cultures that are in conflict in her country. Her empathic attitude is especially notable because it is directed not only at the victims but also at the Whites who committed the abuses and cruelties. Although her

\footnotetext{
${ }^{1}$ The out-group homogeneity effect is the tendency to perceive more variability between members of one's own group (the in-group) than between members of a group that one is not a member of (the out-group) [14].
} 
condemnation of their crimes never falters, she also expresses empathy for the White perpetrators of countless injustices, the torturers responsible for atrocious sufferings. She attempts to understand empathically the psychological roots of violence [11] (p. 195).

This is a view that psychological research has often embraced [15 - 17]. In this paper I aim to expand my previous considerations, which mainly, though not wholly, focused on the content of the work of art, and to view the role of art from a slightly different perspective. This perspective has especially to do with the aesthetic experience per se as well as with the form, that is with the structure and texture of the work of art, and not with its mere content.

\section{AN EXAMPLE OF ART THERAPY APPROACH IN CONNECTION WITH VIOLENCE}

In order to provide a clearer view of my point of view, I will refer to a particular art therapy program, which is illustrated by Awad Alyami, one of his two co-founders [18] and which is used in Saudi Arabia with a population involved in terrorism-related activities.

I will quote a few phrases which are scattered in Alyami's paper and which he uses in presenting the aims and activities of the program, as these phrases can help elicit a useful discussion on some key issues regarding different and at the same time complementary approaches aiming to countervail the problem of violence: "through a safe medium" (p. 1), “art can offer balance" (p. 1), “[art can help participants] express their feelings and thoughts" (p. 1), “[art can help them] address unconscious issues" (p. 2), "[one of the objectives of the program is] to help in the reconstruction of misconceptions, aberrant thoughts, and misguided beliefs" (p. 2).

In the course of this paper, these phrases are discussed with brief comments on them.

The program illustrated by Alyami is based on art creation and, more specifically, on picture-making. Technique instruction was provided to participants; all of them were ex-jihadists. The author stated that the results indicate that this program is an efficacious instrument in combating terrorism.

The main concept underpinning this approach is the idea of art as instrumental to life that is in the service of life. This perspective is also almost explicitly suggested in these lines:

And even though some subjects gained sufficient artistic skill to qualify them as artists, we aimed further than just creating artists; we aimed to build personalities that respect humanity, human dignity and to be a human being who can live peacefully with other people of different backgrounds and beliefs [18] (p. 5).

It is clear that in this perspective, life and art are conceived as two distinct entities, one (art) at the service of (instrumental to) the other (life). We will later see how my perspective partly differs from Alyami's.

It goes without saying that I am not arguing that one perspective is better than the other. Both of them can be considered valid and, I would suggest, complementary.

As indicated by Alyami, who is also the supervisor of the art therapy staff at the MBNCCC (Mohammed Bib Nayer Center for Counseling \& Care) in Riyadh, the program at the MBNCCC addresses participants' specific problems, such as anger, aggressive tendencies, extreme ideas and beliefs, traumatic past events, and worries about one's future. Also some specific aims of the program are presented. For example, the principles of balance and rhythm, which may be important features of a specific painting participants and the art therapist are making, according to the author can prompt a discussion on the importance of these components in life. More in general, subjects are encouraged "to react through art to express any unwanted aggression" (p. 5), "to be soft and kind to people" (p. 5), so as to become individuals who, as said above, "respect humanity, human dignity and [...] can live peacefully with other people of different backgrounds and beliefs" (p. 5).

According to the author, these aims can be achieved also because participants can express their negative feelings "through a safe medium" (p. 1), that is through artistic expression. I will later argue that the artistic form is characterized by a total freedom. The nature of this freedom is such that it is "safe". No harm can ensue either for the person that produces the work of art and for the person that benefits from it. 


\section{ART AS AN INTRINSIC AND INALIENABLE COMPONENT OF LIFE}

In his Lectio Magistralis delivered on $27^{\text {th }}$ March 2013 at the "Milano Bicocca University" in Milan, the Italian jazz player Paolo Fresu [19] stated that art has a fundamental value as it is a language that "penetrates man and the world, weaving the threads that interlace the deepest and most secret parts of ourselves, thus reversing the traditional concepts of seeing and feeling" [19] (pp. 15-16).

In particular, he put forward three important arguments: a) we are witnessing the decline of man; b) this is because we have lost "the thread that links the introspective part of ourselves" (p. 6) with that "society we belong to and which seems to ignore us" (p. 6); c) in this context art can be the key "to re-read the world" (p. 6) and to look at this decline "from another angle" (p. 6). In brief, his thought could be summarized in his words "[...] the world can be better if it is inhabited by the sense of beauty" (p. 15). It is clear that we might easily replace "better" with "less violent".

Though Fresu did not develop his perspective on the role of art in society within a precise socio-psychological theoretical framework, his arguments are somewhat and partly akin to some of the arguments - especially those dealing with the social role of art - presented by Vygotsky in his famous work "The Psychology of Art" [20], where he illustrates his aesthetic theory, highlighting the essence and the aims of the artistic experience.

Thus, it can be useful to summarize some relevant points of his theory:

a. The object of the aesthetic experience, as well as of any critical examination of the work of art itself, is the form, which is the artistic construction and texture of all the elements, including its content, that make up a work of art. These elements are variously and reciprocally organized according to hierarchies of constructive subordinations and connections.

b. It is just this form that produces the special emotion that we name "aesthetic".

c. These various elements in their specific combinations functionally correspond to specific aesthetic experiences, which can thus be reconstructed and identified.

d. Through art it is possible to find "an equilibrium between man and his world, in the most critical and important stages of his life" [20] (p. 259).

e. Art is "a method for building life" [20] (p. 259).

The following are some considerations I elaborated on the basis of Vygotksy's aesthetic theory as well as of Jeanne Hersch's reflections on the interconnections between music and time $[21]^{2}$ :

1. It is clear that the above points d) and e) are especially close to Fresu's beliefs on the role of art in society.

2. It is clear that, with respect to Alyami's view, in both Fresu and Vygotsky's perspectives the aim of art is more "holistic", that is the aesthetic experience is not linked to specific objectives (such as addressing anger and aberrant thoughts), but to a more "general" transformation of the individual and of society. This transformation seems to have many of the connotations of a "rebirth".

3. It is also clear that, in Vygotsky's view, art and life inherently belong to each other. As I said above, this perspective partly contradicts Alyami's choice in carrying out his art therapy program at the MBNCCC. In fact he states that his aim is not principally to create artists but to foster the development of humane and respectful personalities. So it seems that, in his view, art and life are somewhat separate entities and art is at a lower level of importance with respect to life.

4. As Jeanne Hersch poignantly states, art is free and "nourishes our freedom" [21] (p. 80). The idea of freedom that characterizes art seems to have been expressed also by Vygotsky through the concept of "nonmotivated" [20] (p. 223). This means that, unlike what often happens in everyday life, the artistic experience per se is not basically motivated by any "external" element. The motivation of the artistic experience comes from "internal," deep, and partly still "unexplored" elements that belong to the individual, to society, and in a way, to the whole of reality.

\section{ART AS A TRANSFORMING COMPONENT OF LIFE}

When we say that art "nourishes our freedom", here, as mentioned beforehand, the concept of freedom basically refers to the concrete possibility for a human being to become profoundly aware of and to aptly express all her/his

\footnotetext{
${ }^{2}$ Though Hersch's reflections focus strictly on music, I will draw on them in my attempt to identify and analyze the main components of the aesthetic experience. It is a fact that I believe that most of her considerations can be applied to any form of artistic expression.
} 
affective and cognitive potentialities. Thus, if this is so, art can help the individual, groups and society at large to attain a subtler, deeper, and broader knowledge of themselves and of reality in general. Accordingly, art can bring forth a greater awareness of the complexity of individuals, situations, thoughts, emotions, and reality in general. It will then be easier to reduce or avoid unjustified violence, which, as I said above, mainly consists in an irrational and short-sighted analysis and interpretation of reality. It will also be easier to opt for more reasonable, constructive, and benevolent strategies when conflicts arise.

Therefore, we might also say that "art nourishes our knowledge." For example, Collingwood [22, 23] maintains that art is expressive imagination. Through imagination, which especially is the realization that a particular emotion (for example, anger) has been transformed by consciousness, our emotions change (for example, we become less violent). Hence, it appears that this transformation of emotions through imagination, which also corresponds to the faculty of conscious attention, is basically linked to the development of self-consciousness. In connection with this, as we will see later on, we can also possibly claim that art can provide the possibility to experience a new dimension, in which, as suggested by Fresu and by Lee, new ways of "seeing and feeling" [19] (p. 16) or "leaps of imagination" [4] (p. 156) are made possible. Moreover, in the aesthetic experience, freedom and knowledge are inextricably woven into pleasure, so that they actually fuel one another. It is a kind of freedom, knowledge and pleasure that people do not usually experience in other contexts, except possibly in situations of deep understanding and affection in their relations with other individuals, themselves, nature, or with reality in general.

The idea of freedom and the idea of pleasure are clearly reminiscent of Kant's focus on freedom in the aesthetic experience and on the disinterested pleasure connected with it [24]. Interestingly, Kant also believed that disinterestedness is a quality that aesthetic pleasure shares with moral judgment. Here, obviously, the aesthetic pleasure differs from the pleasure we may obtain from a sensuous and pragmatic enjoyment. Kant also claimed that this pleasure, namely the taste of the beautiful, is universal, because beauty is inherent to the thing that produced the experience of beauty. Besides, through this experience, the individual is connected with "the real existence" of the thing itself: a deeper and new kind of knowledge through which also self-awareness is bolstered.

I would also like to put forth another important point. I argue that, while in this dimension, new ways of "seeing and feeling" [19] (p. 16) and "leaps of imagination" [4] (p. 156) are made possible, here no violence is possible, especially because in this dimension, power relationships do not exist.

It is a fact that in our past and present societies, a competitive life pattern and, consequently, power relationships have permeated human lives very often [6, 12, 25 - 30]. It is also a fact that power relationships are at the basis of aggressive attitudes and behavior [25, 30]. I have already mentioned freedom, as one of the basic components of the aesthetic experience. In the aesthetic experience, freedom is basically related to the absence of the limitations imposed by unnecessary and noxious power relations. In this context, emotions and thoughts are experienced, expressed, and analysed per se, in all their various facets and complexities. Here, the absence of concern for power relations produces a unique and precious outcome: the mind is more free, so that knowledge, and awareness in particular, are naturally expanded and enriched. Consequently, aggression and violence, which - as I said above - are basically at the roots of power relations, naturally lose their raison d'être.

This particular dimension, which Hersch defines "a miniature of eternity" [21] (p. 90), thus implicitly underlying its difference from what usually characterizes the most frequent experiences in everyday life, corresponds to "those wondrous places of the soul" [19] (p. 18) which Fresu envisaged as the main destination of the aesthetic experience connected with music.

In these "wondrous places of the soul", there is no place for violence because here human beings can freely and deeply communicate with each other and with the rest of reality, a situation that also corresponds to the "inner experience of heightened life that comes from having meaning", described by Lee [4] (p. 154).

Finally, I would like to go back once more to Vygotsky's position about the unique role played by the form in the aesthetic experience. As I said above, he is extremely clear and poignant on this point, which is the foundation of his aesthetic theory. He is so clear and poignant as to include in "The Psychology of Art", and thoroughly analyse as an exemplar, a short story by Bunin entitled "Gentle Breath".

The content of the story, its "anatomy" or "disposition", as Vygotsky also refers to it, falls under the category "troubles of life" [20] (p. 152) or life's "turbid waters" [20] (p. 154). But - he writes - "Surprisingly [...] the effect of the story, as a whole, is somewhat different." [20] (p. 154) Indeed, "the complex structural curve of reality" [20] (p. 
154), which is the form, as opposed to the "straight line of reality" [20] (p. 154), which is the material of the story taken per se, is its "light breath" and "life's turbidity" is transformed into a "crystal transparency." [20] (p. 154). So, in Vygotsky's view, the artistic form produces a transformation of reality or, more exactly, creates a new reality where no one can do or be exposed to any real harm. So he writes:

The words of a story or verse carry its meaning (the water), whereas the composition creates another meaning for the words, transposes everything onto a completely different level, and transforms the whole into wine. Thus, the banal tale of a frivolous provincial schoolgirl is transformed into the gentle breath of Bunin's short story [20] (pp. 154-155).

Vygotsky's considerations are also reminiscent of Clive Bell's [31] ideas on the essence of the aesthetic experience, which he deemed to be rooted in a special quality of the work of art, namely in its "significant form" (p. 8). This quality only pertains to the world of art, and it is this quality that differentiates the realm of art from the realm of life (the form as opposed to "the straight line of reality", in Vygotsky's enunciation). Interestingly Bell also, like Kant, identifies the aesthetic experience of "the rightness" (p. 26) of the forms of a work of art with a pure intellectual experience. Bell also seems to tinge art with a deep moral meaning, by stating that "art might prove the world's salvation" (p. 35).

\section{CONCLUSION: ART AS A " LANGUAGE FOR LIFE"}

In her speech, delivered in 1999 at the University of Bologna, when she received an honorary doctorate from this university [32], Pina Bausch said that in the artistic creation we have to find a language able to communicate something that has always existed in ourselves. She also said that this "something" is a very precise knowledge ("indeed our sentiments" - she said - "are very precise"), which everybody possesses, and that dance, music, etc. are very exact languages, through which we can communicate this knowledge. She added that this has to do with life, and so, what has to be done is to find a language for life.

There are two important points in Pina Bausch's words that are particularly relevant here. One is obviously the inextricable interconnection of life and art, a perspective I have already examined in this paper. The other is her reference to a knowledge that we have always possessed. This remark brings us back to those worlds of our consciousness - the subconscious and the unconscious, but also, possibly, the still unexplored domains of extended consciousness [33] - where it is difficult to enter but which constitute (or might constitute in the case of extended consciousness) an enormous reservoir of knowledge and experience. Art can help us bring them to life again. Thus, it can foster the development of less primitive, richer, fuller, more complete and complex personalities. In this way, as I said above, violence should automatically vanish and lose its raison d'être.

So it appears that pleasure, knowledge, and morals are all essential constituents of the aesthetic experience.

Vygotsky uses a metaphorical image - the image of wine - to describe the new reality created by the artistic form, which completely transforms what might have just been the banal description in the crime news of a newspaper of the murder of a provincial schoolgirl. Instead, through the artistic form, the story becomes unique, all the characters are equally important, meaningful, necessary, and practically "immortal", and the reader can, in a way, come into contact with a sort of transcendence. This is an experience that can certainly shed much light in the visions and perspectives of our everyday lives.

So it appears that art can teach us to live. And art might be even better than science at this job, as the Latin poet Virgil wrote that art is capable of revealing to us what no science can ever reveal to a human mind.

\section{CONFLICT OF INTEREST}

The author confirms that this article content has no conflict of interest.

\section{ACKNOWLEDGEMENTS}

Declared none.

\section{REFERENCES}

[1] Munro T. Art and violence. J Aesthet Art Crit 1969; 27: 317-22.

[http://dx.doi.org/10.2307/428677] 
[2] Pagani C. Violence and complexity. Open Psychol J 2015; 8: 11-6. [http://dx.doi.org/10.2174/1874350101508010011]

[3] Robustelli F. Rationality as an alternative to violence. Prometeo (Milan) 2005; 89: 96-101.

[4] Lee BX. Causes and cures IV: The symbolism of violence. Aggress Violent Behav 2016; 27: 152-7. [http://dx.doi.org/10.1016/j.avb.2016.03.002]

[5] Pagani C, Robustelli F, Ascione FR. Animal abuse experiences described by school-aged children. In: Ascione FR, Ed. The International Handbook of Animal Abuse and Cruelty: Theory, Research, and Application. West Lafayette, IN: Purdue University Press 2008; pp. 247-68.

[6] Cangià F, Pagani C. Youths, cultural diversity, and complex thinking. Open Psychol J 2014; 7: 20-8. [http://dx.doi.org/10.2174/1874350101407010020]

[7] Pagani C. Youth's empathy and complex thinking. In: Wain V, Pinomo P, Eds. Encountering Empathy: Interrogating the Past, Envisioning the Future. Oxford: Inter-Disciplinary Press 2015; pp. 177-88.

[8] Pagani C. Empathy, complex thinking, and their interconnections. In: Nelems R, King C, Theo LJ, Eds. Exploring Empathy: Perimeters, Propagations and Positionings. Oxford: Inter-Disciplinary Press [in press].

[9] Morin E. On Complexity. Cresskill: Hampton Press 2008.

[10] Ezekiel RS. An ethnographer looks at neo-nazi and klan groups: the racist mind revisited. Am Behav Sci 2002; 46: 51-71. [http://dx.doi.org/10.1177/0002764202046001005]

[11] Pagani C. The cross-cultural significance of empathy as an instrument to prevent aggression. In: Ramirez JM, Richardson DS, Eds. Crosscultural Approaches to Aggression and Reconciliation. Huntington, NY: NovaScience 2001; pp. 191-201.

[12] Pagani C. Diversity and social cohesion. Intercult Educ 2014; 25: 300-11. [http://dx.doi.org/10.1080/14675986.2014.926158]

[13] Pagani C, Robustelli F. Young people, multiculturalism, and educational interventions for the development of empathy. Int Soc Sci J 2010; 61(200-201): 247-61. [http://dx.doi.org/10.1111/j.1468-2451.2011.01761.x] [PMID: 21898944]

[14] Brewer MB. The psychology of prejudice: ingroup love or outgroup hate? J Soc Issues 1999; 55: 429-44. [http://dx.doi.org/10.1111/0022-4537.00126]

[15] Giles HJ, Hajda M, Hamilton DL. Harmony and discord: the music of intergroup relations. Group Process Intergroup Relat 2009 ; $12: 290$. [http://dx.doi.org/10.1177/1368430209102207]

[16] Giles HJ, Denes A, Hamilton DL, et al. Striking a chord: a prelude to music and intergroup relations research. Group Process Intergroup Relat 2009; 12: 291-301. [http://dx.doi.org/10.1177/1368430209102840]

[17] Rodríguez-Bailón R, Ruiz J, Moya M. The impact of music on automatically activated attitudes: flamenco and gypsy people. Group Process Intergroup Relat 2009; 12: 381-96. [http://dx.doi.org/10.1177/1368430209102849]

[18] Alyami A. The role of art therapy in counterterrorism: the Saudi experience. Arts Psychother 2015; $44: 1-10$. [http://dx.doi.org/10.1016/j.aip.2015.04.003]

[19] Fresu P. The Impossible Possible, 2013, Available from: http://www.paolofresu.it/upload/gestione_files/pdf/lectio-magistralis1422615519.pdf

[20] Vygotsky LV. The Psychology of Art. Cambridge, Massachusetts: The M.I.T. Press 1971. [Original work published 1925].

[21] Hersch J. Tempo e Musica Con un saluto di Czesłav Miłosz. Milano: Baldini Castoldi Dalai 2009 [Original work published 1990].

[22] Collingwood RG. The Principles of Art. London: Oxford University Press 1938.

[23] Kemp G. Collingwood's Aesthetics. In: Zalta EN, Ed. The Stanford Encyclopedia of Philosophy (Fall 2016 Edition), forthcoming, 2016, Available from: http://plato.stanford.edu/archives/fall2016/entries/collingwood-aesthetics/ .

[24] Kant I. Critique of Judgement. Translated by James Creed Meredith. Oxford: Oxford University Press 2007. Oxford World's Classics. [original work published 1952]. ISBN 978-0-19-280617-8.

[25] Pagani C. Perception of a common fate in human-animal relations and its relevance to our concern for animals. Anthrozoos 2000; 13 : 66-73. [http://dx.doi.org/10.2752/089279300786999879]

[26] Pagani C. Children and Adolescents who are Kind to Animals. In: Blazina C, Shen-Miller DS, Boyraz G, Eds. The Psychology of the HumanAnimal Bond: A Handbook for Clinicians and Researchers. New York: Springer 2011; pp. 289-305. [http://dx.doi.org/10.1007/978-1-4419-9761-6_17]

[27] Pagani C. Fear, hate, anger, resentment, and envy in youths' racist attitudes toward immigrants. In: Ramirez JM, Morrison C, Kendall A, Eds. Conflict, Violence, Terrorism, and their Prevention. Newcastle upon Tyne, UK: Cambridge Scholars Publishing 2014; pp. 16-27.

[28] Pagani C, Robustelli F. Youth's attitudes toward racism: a psycho-socio-cultural perspective. In: Szegál B, András I, Eds. Conflicts in a Society in Transition, Dunaújváros: Dunaújváros College Press. 2011; pp. 79-95. 
[29] Pagani C, Robustelli F, Martinelli C. School, cultural diversity, multiculturalism, and contact. Intercult Educ 2011; 22: 337-49. [http://dx.doi.org/10.1080/14675986.2011.617427]

[30] Robustelli F, Pagani C. L'educazione contro la violenza (Education against violence). Psicologia contemporanea 1996; 136: 4-10.

[31] Bell C. Art. New York: Frederick Abbott Stokes Company Publishers 1913.

[32] Bausch P. Discorso di Pina Bausch per la laurea ad honorem conferitale dall'Università di Bologna nel 1999 (Pina Bausch's speech, delivered when she received an honorary degree from the University of Bologna in 1999). Available from: http://danzaworld.forumcommunity.net/ $? \mathrm{t}=53253365$ \#lastpost

[33] Shamdasani S, Ed. C G Jung The Psychology of Kundalini Yoga Notes of the Seminar Given in 1932 by Jung. CG Bollinger Series XCIX. Princeton: Princeton University Press 1996.

(C) Camilla Pagani; Licensee Bentham Open

This is an open access article licensed under the terms of the Creative Commons Attribution-Non-Commercial 4.0 International Public License (CC BY-NC 4.0) (https://creativecommons.org/licenses/by-nc/4.0/legalcode), which permits unrestricted, non-commercial use, distribution and reproduction in any medium, provided the work is properly cited. 